\title{
Coupled Hydro-Mechanical Analysis of Rainfall-Induced Instability of Non-Uniform Soil Slopes
}

\author{
Manyu WANG ${ }^{\mathrm{a}}$, Yong LIU ${ }^{\mathrm{a}, 1} \mathrm{Lu} \mathrm{YANG}^{\mathrm{b}}$, Jing WU ${ }^{\mathrm{b}}$ and Guilin NIU ${ }^{\mathrm{b}}$ \\ ${ }^{a}$ State Key Laboratory of Water Resources and Hydropower Engineering Science, \\ Institute of Engineering Risk and Disaster Prevention, Wuhan University, 299 Bayi \\ Road, Wuhan 430072, P. R. China \\ ${ }^{\mathrm{b}}$ Hebei Research Institute of Investigation \& Design of Water Conservancy \& \\ Hydropower, Tianjin 300250, P. R. China
}

\begin{abstract}
In recent years, more considerable attentions are paying on the hazards of large-scale landslides induced by heavy rainfall. However, the heterogeneity in hydraulic properties of soils may affect the seepage pattern of water infiltrated into soil slopes. Inspired by this fact, this paper aimed to evaluate the effect of the spatial variability in hydraulic conductivity on failure mechanism of an unsaturated soil slope subjected to rainfall infiltration, being implemented in the framework of a transient coupled hydro-mechanical analysis. The concept of random field was adopted to model the spatial randomness of saturated hydraulic conductivity $k_{\mathrm{s}}$ following a uniform distribution. The finite element method was then incorporated to conduct Monte Carlo simulations. The resultant findings show that the mode of shallow slope failure is more likely to occur than the deep one due mainly to the highly variable distribution of $k_{\mathrm{s}}$ near slope surface. Note that the decrease in the effective stress of soils resulting from the increase of pore water pressure is the most critical reason for the occurrence of slope failure. In addition, from the random element analyses results, it indicates that the value of $Q_{\text {ari }}$ calculated by performing a deterministic analysis based on arithmetic average value $k_{\text {ari }}$ gives a prediction of flow rate on average, but the calculated $Q_{\max }$ based on maximum value $k_{\max }$ provides a more conservative assessment on total flow rate across soil slope, which can offer useful suggestions for practitioners to take available measures to drain in advance.
\end{abstract}

Keywords. Coupled hydro-mechanical analysis, Landslides, Rainfall infiltration, Hydraulic conductivity, Spatial variability, Random finite element analysis.

\section{Introduction}

Rainfall-induced landslides are one of the most common geotechnical disasters in practice (e.g. a landslide event shown in figure 1a), often resulting in severe threats to both the human safety and surrounding buildings [1-3]. Actually, the phenomenon of a rainfall-induced landslide is a typical coupled hydro-mechanical problem from the viewpoint of physical mechanics, which is of great interest in the risk assessment of

\footnotetext{
${ }^{1}$ Yong Liu, State Key Laboratory of Water Resources and Hydropower Engineering Science, Institute of Engineering Risk and Disaster Prevention, Wuhan University, 299 Bayi Road, Wuhan 430072, P. R. China; E-mail: liuy203@whu.edu.cn.
} 
landslides [4]. When heavy rainfall occurs, the hydraulic conductivity of soil directly influences the hydraulic output responses relating to slope performances [5]. Generally, deterministic methods were widely adopted for the stability assessment of rainfallinduced landslides $[2,4,6]$. In reality, however, the physical properties of natural soils are highly variable in space $[1,5,7,8]$. During the infiltration of rainfall into soil slopes, the uncertainty in the distribution of pore water pressure, caused by heterogeneous hydraulic conductivity, may be the main source of slope instability due to the fact that it is likely to affect the shear strength of soils [2].

Various studies have investigated the influence of the spatial variation of hydraulic conductivity on soil slope stability. For instance, Cho [5] conducted probabilistic stability analyses to study the effects of spatial heterogeneity of saturated hydraulic conductivity on the failure mechanism of rainfall-related shallow infinite landslides. However, a common assumption was made in their studies; that is, the hydraulic conductivity was usually modeled as a lognormal random field. This may be not an appropriate consideration because the saturated hydraulic conductivity of soil in a limited space generally varies over one to three orders of magnitude or even large [9]. Therefore, using a marginal uniform distribution for the representation of saturated hydraulic conductivity may be more reasonable because of the equal likelihood of data of each point being retrieved from situ field.

This paper mainly aimed to evaluate the effect of spatially variable hydraulic conductivity on the failure mechanism of a soil slope suffering from rainfall infiltration. Moreover, it should be noted that for simplicity the strength properties of soils were treated as deterministic for the whole slope model.

\section{Governing Equations of Coupled Hydro-mechanical Behavior of Unsaturated Soils}

In general, coupled solutions related to the soil structure and water flow are required to simulate the process of seepage and deformation in a soil slope subjected to rainfall. Due the complexity of unsaturated soils, the effective stress state variable is used in the slope stability analysis:

$$
\sigma^{\prime}=\sigma-u_{a}+\chi\left(u_{a}-u_{w}\right)
$$

where $\sigma^{\prime}$ is the effective stress; $u_{a}$ is the pore air pressure, which is equal to zero because the air phase within soil is assumed to be connected with atmosphere; $u_{w}$ is the pore water pressure, and $\left(u_{a}-u_{w}\right)$ is the matric suction; $\chi$ is the unsaturated soil parameter between zero and unity, which is equal to degree of saturation $(S)$ in this study. Transient water flow through the pore of unsaturated soils follows the generalized Darcy's law. A number of empirical and semi-empirical functions have been proposed to represent these soil hydraulic functions. In this study, the van Genuchten [10] and Mualem [11] (VGM) model was adopted for describing the unsaturated hydraulic functions, which can be written as: 


$$
\begin{gathered}
S=\frac{\theta_{w}-\theta_{r}}{\theta_{s}-\theta_{r}}=\left\{\begin{array}{cc}
\left(1+\left|\alpha_{w} u_{w}\right|^{n_{w}}\right)^{-m_{w}} & u_{w}<0 \\
1 & u_{w} \geq 0
\end{array}\right. \\
k(S)=k_{s} S^{1 / 2}\left[1-\left(1-S^{1 / m_{w}}\right)^{m_{w}}\right]^{2}
\end{gathered}
$$

where $\theta_{w}$ is the volumetric water content; $\theta_{s}$ and $\theta_{r}$ denote the saturated and residual volumetric water content, respectively; $\alpha_{w}, n_{w}$, and $m_{w}$ are retention parameters, with $m_{w}=\left(1-1 / n_{w}\right) ; k$ is the hydraulic conductivity of soils, changing as a function of $S ; k_{s}$ is the saturated hydraulic conductivity.

\section{Methodology}

\subsection{Coupled Modeling of an Unsaturated Soil Slope}

In this study, a soil slope subjected to rainfall was considered, as depicted in figure $1 \mathrm{~b}$. The finite element model consists of 625 four-node quadrilateral elements with full integration. The soil slope with a height of $30 \mathrm{~m}$ is inclined at $40^{\circ}$ to the horizontal. The initial ground water table is assumed to be horizontal and located at the lower slope toe surface. Above the water table, the pore pressure is negative and assumed to be proportional to the vertical distance from the water table. The left and right boundaries of this model were constrained in the horizontal direction, and the bottom was fixed in all directions.

In order to simulate the process of rainfall infiltrating into soil slope, a water flux $q$ was controlled as a seepage boundary condition at the slope free surface $a b c d$. The corresponding rainfall intensity shown in figure $1 \mathrm{~b}$ was applied to reflect the real scenarios that the rainfall increases gradually with duration time. For surface $b c$, the rainfall intensity was set to the value of $q \times \cos 40^{\circ}$. With the purpose of assessing the slope stability under rainfall conditions, four monitoring points near slope surface denoted in figure $1 \mathrm{~b}$ were set up to obtain some important responses associated with slope sliding at different rainfall times.

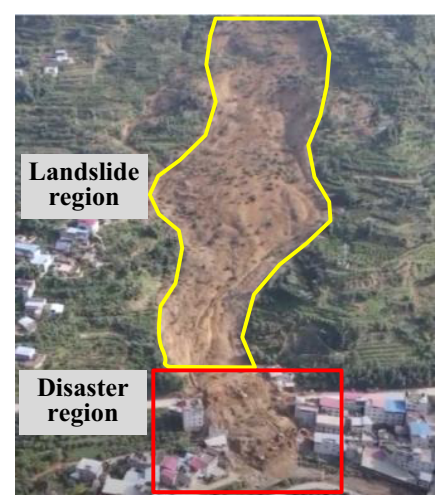

(a)

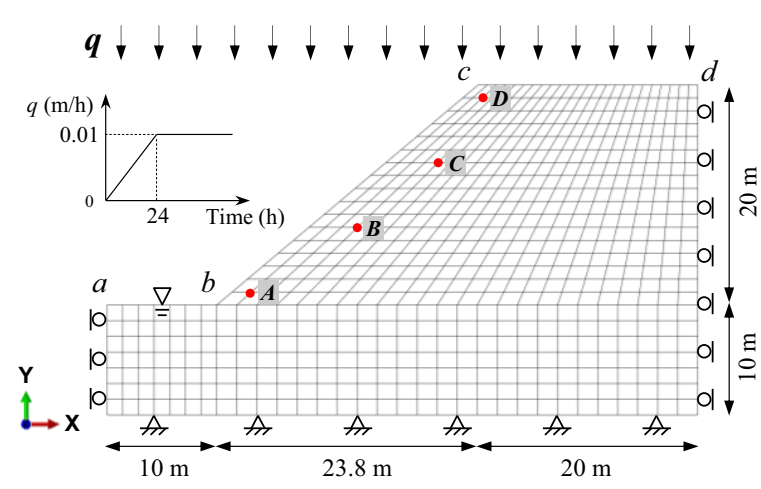

(b)

Figure 1. (a) A typical event of rainfall-induced landslide; (b) soil profile of a coupled hydro-mechanical slope model analysed in this study. 


\subsection{Spatial Variability in Saturated Hydraulic Conductivity}

Unlike to previous literatures, the saturated hydraulic conductivity $k_{\mathrm{s}}$ was modeled as a random field following a uniform distribution in this study. To reach this goal, a Gaussian random field with a squared exponential auto-correlation structure was first generated using the modified linear estimation method [7], and the uniform random field could then be obtained through a memoryless translation. The latter is a special case of beta random field that can be translated from the former. The range of the value of $k_{\mathrm{s}}$ used in the analysis varies from 0.0018 to $0.018 \mathrm{~m} / \mathrm{h}$. Two typical realizations of $k_{\mathrm{s}}$ field are shown in figures $2 \mathrm{a}$ and $2 \mathrm{~b}$. In order to perform a comparison with the results of random element analyses, deterministic analyses were also conducted based on the several constant values of $k_{\mathrm{s}}$; they are the minimum value $k_{\mathrm{min}}$, the magnitude average value $k_{\mathrm{mag}}$, the arithmetic average value $k_{\text {ari }}$, and the maximum value $k_{\max }$ of the selected range, respectively. The parameters of soil properties used are summarized in table 1.

Without loss of generality, the $k_{\mathrm{s}}$ field was then incorporated with finite element program to perform the coupled analysis of soil slope. 100 realizations of $k_{\mathrm{s}}$ field were conducted to evaluate qualitatively the spatial randomness effect of hydraulic property on slope performance in a statistical manner.

Table 1. Parameters of soil properties used in the coupled analysis.

\begin{tabular}{lll}
\hline Parameter & Definition & Value \\
\hline$E(\mathrm{kPa})$ & Elasticity modulus & 10,000 \\
$v$ & Poisson's ratio & 0.3 \\
$c^{\prime}(\mathrm{kPa})$ & Effective cohesion & 15 \\
$\varphi^{\prime}\left({ }^{\circ}\right)$ & Effective internal friction angle & 30 \\
$k_{\mathrm{s}}(\mathrm{m} / \mathrm{h})$ & Saturated hydraulic conductivity, random field & $0.0018-0.018$ \\
$\alpha_{w}\left(\mathrm{kPa}^{-1}\right), n_{w}, \theta_{r}$ & Retention parameters & $0.05,1.2,0$ \\
\hline
\end{tabular}

\section{Results and Discussion}

\subsection{Mode of Slope Failure Induced by Rainfall Infiltration}

Figure 3 shows the results of normalized horizontal displacement (i.e. $D / H$, where $H$ is the slope height of $20 \mathrm{~m}$ ) of four monitoring points against rainfall duration time. Two modes of slope failure, both the shallow and deep failures, can be observed. The region $T$ denoted in figure 3 illustrates the variation range of beginning time for slope to slide, and the discrepancy reaches about 10 hours. This is because that the infiltration of rainfall takes different times to flow to the slope toe due to regular seepage paths resulting from the spatially random $k_{\mathrm{s}}$. With the concentration of water, the pore water pressure increases and the effective stress of soil skeleton reduces, eventually resulting in a slope failure. From figure 3, it can be found that the earlier the beginning time of sliding, the larger is the possibility of a shallow slope failure. This may be attributed to the scenario in which the large hydraulic conductivity exists and concentrates near the lower slope surface. Figures $2 \mathrm{a}$ and $2 \mathrm{c}$ illustrate a typical $k_{\mathrm{s}}$ distribution and its corresponding critical slip surface of a shallow slope failure, respectively. This can be preliminarily judged by the occurred displacement of monitoring points $A$ and $B$. 
Another mode is the deep slope failure, of which the displacement of the upper monitoring points increases significantly with the increase of rainfall duration. At the stage approaching failure, a sharp fall in displacement occurs. Figure 4 presents the evolution of a typical deep slope failure based on the realization shown in figure $2 \mathrm{~b}$. The contour of $k_{\mathrm{s}}$ field in figure $2 \mathrm{~b}$ shows that several local regions with a large hydraulic conductivity exist near the slope surface but they are not connected. As shown in figure $2 \mathrm{~d}$, during the process of rainfall, the water within soil slope is more likely to flow toward those regions. As expected, a local slip surface nearby the slope toe is first formed and then moves slowly toward to the upper slope surface. When rainfall continues, the pore water pressure increases quickly, and a critical slip surface across the slope crest can be observed at the stage of slope failure

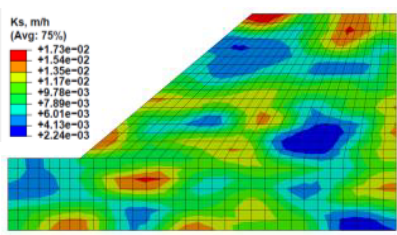

(a)

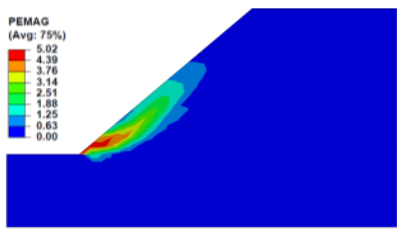

(c)

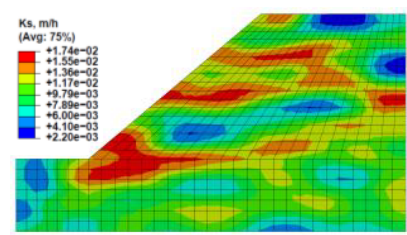

(b)

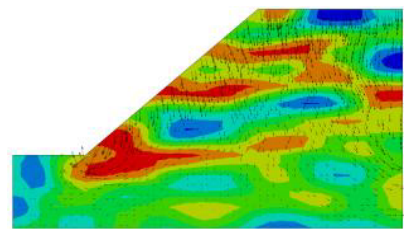

(d)

Figure 2. (a) and (b) Two typical realizations of $k_{\mathrm{s}}$ field; (c) a shallow slope failure based on figure $2 \mathrm{a}$; (d) the seepage velocity vectors based on figure $2 \mathrm{~b}$.

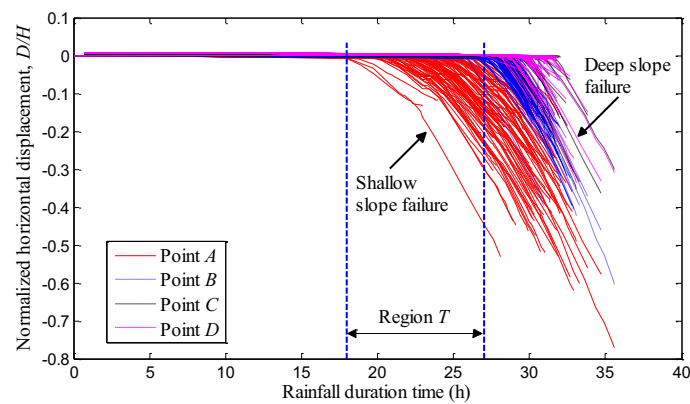

Figure 3. Contours of normalized horizontal displacement of four monitoring points against rainfall duration time based on 100 realizations of Monte Carlo simulations.

\subsection{Assessment of Flow Rate after Slope Failure}

Figure 5 shows the histogram of total flow rate $Q$ across the entire soil slope after slope failure, which was calculated from 100 realizations of Monte Carlo simulations; the corresponding mean and coefficient of variation are 3.6 and 0.07 , respectively. Four vertical dashed lines labelled in figure 5 denote the corresponding flow rates (i.e. $Q_{\min }$, $Q_{\text {mag }}, Q_{\text {ari }}$, and $Q_{\max }$ ) calculated by performing deterministic analyses based on these 
constants of hydraulic conductivity as explained in Section 3.2. All these values of flow rate obtained from random element analyses are between $Q_{\min }$ and $Q_{\max }$, which demonstrates the rationality of coupled analysis results. Note that although the calculated flow rate is relevant to the mode of slope failure and rainfall time, the uncertainty in prediction of the amount of infiltration water can be represented basically. It can be found that the flow rate $Q_{\text {ari }}$ gives a basic reflection on the average state of these random results, but it may underestimate the possible larger value caused by the strongly spatial variability of $k_{\mathrm{s}}$. In contrast, if the upper bound value $k_{\max }$ of the selected range of $k_{\mathrm{s}}$ is employed to perform the deterministic coupled analysis, the corresponding value $Q_{\max }$ can provide a more conservative estimation of the total flow rate from the point of engineering safety. Therefore, these results indicate the necessity of considering the spatial heterogeneity in hydraulic conductivity when conducting the coupled analysis of an unsaturated soil slope subjected to rainfall infiltration.

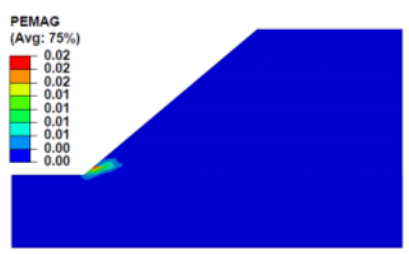

(a) After $17.5 \mathrm{~h}$

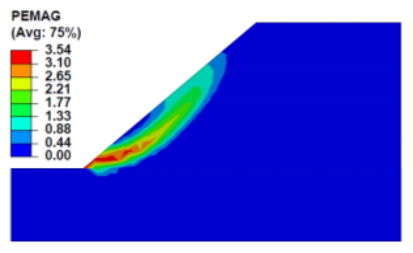

(c) After $31.5 \mathrm{~h}$

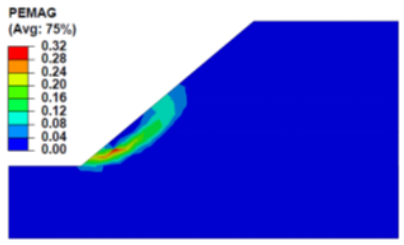

(b) After $25.5 \mathrm{~h}$

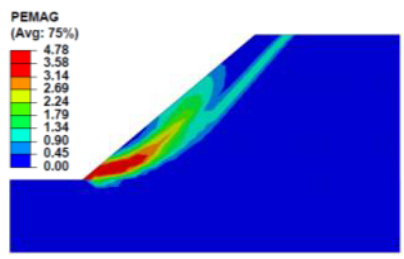

(d) After $32.5 \mathrm{~h}$

Figure 4. Evolution of critical slip surface with rainfall time for a deep slope failure mode based on the typical realization shown in figure $2 b$.

\section{Conclusions}

In this paper, a series of transient coupled hydro-mechanical analyses were conducted to evaluate the effect of the spatial variability in hydraulic conductivity on failure mechanism of an unsaturated soil slope under rainfall condition. The results indicate that two typical modes of slope failure are likely to occur. The occurrence possibility of a shallow slope failure is greater than the deep one, which depends mainly on the distribution of $k_{\mathrm{s}}$ and its connectivity near the slope surface. The primary reason for these slope failures caused by rainfall infiltration may be attributed to the fact that the increase of pore water pressure results in the reduction of the effective stress of soil skeletons, and the critical slip surface develops progressively with rainfall duration. Moreover, the investigation on total flow rate across slope after failure shows that although the value of $Q_{\text {ari }}$ calculated based on arithmetic average value $k_{\text {ari }}$ reflects the average state of flow rate in the random analyses, the obtained $Q_{\max }$ based on maximum value $k_{\max }$ can provide a more conservative assessment on the total flow rate that is likely to occur in potential scenarios. As a result of the limitation of text length, the 
spatial variability in shear strength parameters of soils was not considered together in this paper, but which forms a strand of future works.

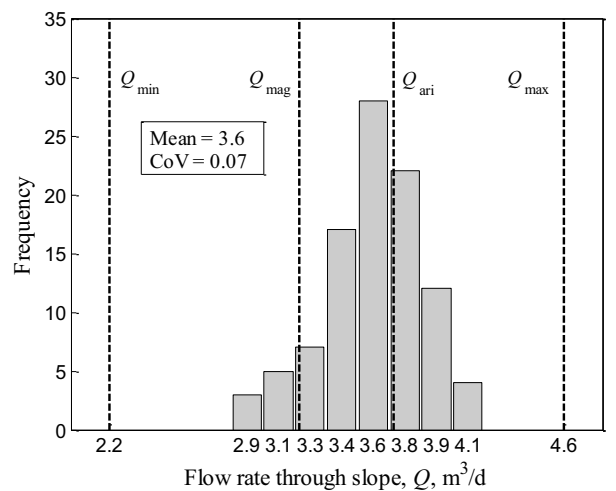

Figure 5. Histogram of total flow rate across soil slope after failure obtained from 100 realizations. CoV = coefficient of variation.

\section{Acknowledgments}

This research is supported by the National Natural Science Foundation of China (Grant No. 51879203 and 52079099).

\section{References}

[1] Dou HQ, Han TC, Gong XN, Zhang J. Probabilistic slope stability analysis considering the variability of hydraulic conductivity under rainfall infiltration-redistribution conditions. Engineering Geology. 2014 Sep; 183: 1-13.

[2] Zhang L, Wu F, Zheng Y, Chen L, Zhang J, Li X. Probabilistic calibration of a coupled hydromechanical slope stability model with integration of multiple observations. Georisk: Assessment and Management of Risk for Engineered Systems and Geohazards. 2018 Feb; 12(3): 169-182.

[3] Johari A, Talebi A. Stochastic analysis of rainfall-induced slope instability and steady-state seepage flow using random finite-element method. International Journal of Geomechanics. 2019 May; 19(8): 04019085.

[4] Tang Y, Wu W, Yin K, Wang S, Lei G. A hydro-mechanical coupled analysis of rainfall induced landslide using a hypoplastic constitutive model. Computers and Geotechnics. 2019 Apr; 112: 284-292.

[5] Cho SE. Probabilistic stability analysis of rainfall-induced landslides considering spatial variability of permeability. Engineering Geology. 2014 Jan; 171: 11-20.

[6] Lu N, Godt J. Infinite slope stability under steady unsaturated seepage conditions. Water Resources Research. 2008 Nov; 44(11): 1-13.

[7] Liu Y, Lee FH, Quek ST, Beer M. Modified linear estimation method for generating multi-dimensional multi-variate Gaussian field in modelling material properties. Probabilistic Engineering Mechanics. 2014 Sep; 38: 42-53.

[8] Wang MY, Liu Y, Ding YN, Yi BL. Probabilistic stability analyses of multi-stage soil slopes by bivariate random fields and finite element methods. Computers and Geotechnics. 2020 Jun; 122: 103529.

[9] Reid ME. Slope instability caused by small variations in hydraulic conductivity. Journal of Geotechnical and Geoenvironmental Engineering. 1997 Aug; 123(8): 717-725.

[10] van Genuchten MT. A closed-form equation for predicting the hydraulic conductivity of unsaturated soils. Soil Science Society of America Journal. 1980 May; 44(5): 892-898.

[11] Mualem Y. A new model for predicting the hydraulic conductivity of unsaturated porous media. Water Resources Research. 1976 Jun; 12(3): 513-522. 